\title{
Correction to: the relative importance of subjective and structural factors for individual adaptation to climate change by forest owners in Sweden
}

\author{
Gregor Vulturius $^{1,2}$ - Karin André ${ }^{1}$ A Åsa Gerger Swartling ${ }^{1}$ - Calum Brown ${ }^{3}$. \\ Mark D. A. Rounsevell ${ }^{2,3}$ • Anna Maria Jönsson ${ }^{4}$ - Victor Blanco ${ }^{2}$
}

Published online: 12 October 2017

(C) Springer-Verlag GmbH Germany 2017

\section{Correction to: Reg Environ Change}

$$
\text { https://doi.org/10.1007/s10113-017-1218-1 }
$$

The published online version contains mistake. Anna Maria Jönsson was inadvertently omitted in the author group section. Correct author group section is shown above.

\footnotetext{
Gregor Vulturius

gregor.vulturius@sei-international.org
}

1 Stockholm Environment Institute, Linnégatan, 87D, 115 23 Stockholm, Sweden

2 School of Geosciences, University of Edinburgh, Drummond Street, Edinburgh EH8 9XP, United Kingdom

3 Institute of Meteorology and Climate Research - Atmospheric Environmental Research, Karlsruhe Institute of Technology, Kreuzeckbahnstraße 19, 82467 Garmisch-Partenkirchen, Germany

4 Department of Physical Geography and Ecosystem Science, Lund University, Sölvegatan 12, 22362 Lund, Sweden 